\title{
Fulminate anaerobic bacteremia after chemotherapy for metastatic breast cancer despite the prophylactic use of GCSF
}

This article was published in the following Dove Press journal:

International Medical Case Reports Journal

II April 2010

Number of times this article has been viewed

\author{
Mila Petrova' \\ Zhasmina Mihaylova' \\ Albena Fakirova ${ }^{2}$ \\ 'Clinic of Hematology and Oncology, \\ Department of Medical Oncology; \\ 2Department of Pathology, Medical \\ Military Academy, Sofia, Bulgaria
}

\begin{abstract}
Chemotherapy-induced neutropenia often occurs in our routine work and presents an obstacle for adequate (dose and continuance) treatment, which may affect patients' outcome. Granulocyte colony-stimulating factors (GCSFs) effectively prevent myelosuppression and thus improve the standard treatment. Through their application cases of chemotherapyinduced neutropenia have been reduced. Still these factors cannot remove entirely the danger of encountering neutropenia, which can cause dangerous complications. We present a case of a fulminate anaerobic infection with unknown origin in a patient with metastatic breast cancer after standard treatment with chemotherapy supported by GCSFs.

Keywords: neutropenia, granulocyte colony-stimulating factors, anaerobic infection, phlegmon
\end{abstract}

\section{Introduction}

In some patients with neutropenic episodes during chemotherapy treatment, reduction of the standard dose and/or prolongation of the intervals between cycles is necessary. Occasionally life-threatening neutropenia-induced complications may occur. ${ }^{1}$ In recent years most international guidelines recommend the prophylactic use of granulocyte colony-stimulating factors (GCSFs) when the risk of developing febrile neutropenia after chemotherapy is greater than $20 \%{ }^{2}$ We report a case of fulminate anaerobic bacteremia after a standard chemotherapy course for metastatic breast cancer with prophylactic use of GCSF, which resulted in the death of the patient.

A 56-year-old woman with no family history of breast or ovarian cancer was diagnosed in November 2004 with cancer of her left breast. Because of the patient's refusal to have a mastectomy, a quadrantectomy was performed. Intraoperatively a tumor mass $3.5 / 3 \mathrm{~cm}$ diameters was found and two lymph nodes out of the 12 dissected were positive (pT2N1M0). The pathology report revealed anaplastic invasive lobular cancer with positive hormone receptors and negative human epidermal growth factor receptor 2 (HER2) status. The chest X-ray and bone scan were also unremarkable. After the organ-preserving operation, radiation of the chest ( $50 \mathrm{~Gy}$ ) and four courses of adjuvant FEC (fluorouracil [5FU], epirubicin and cyclophosphamide). chemotherapy were established. The patient refused adjuvant hormone treatment, and no follow-up was done.

In January 2009 (after a disease-free period of four years) the patient reported symptoms of tiredness, shortness of breath and a cough. A computed tomography (CT) scan of the lungs revealed pleural effusion on the left mediastinal and hilar lymph node enlargement. A bronchoscopy was performed which revealed deformation
Correspondence: Mila Petrova I, G. Sofiisky Blvd., I606 Sofia, Bulgaria Tel +359883335955

Fax +35929226072

Email milllapetrova@gmail.com 
of, and pressure on the left upper bronchus. The histology report confirmed that the lung and pleural lesions were due to metastases from the breast cancer.

In February 2009 the patient was referred to our department. Except for permanent tiredness and a dry cough she revealed no other complaints. The physical status showed restricted breathing in the low parts of the left thorax, tachycardia and muffled heart tones. The breast examination did not show any pathological tumor masses. The complete blood count (CBC) and liver and kidney functions were within the normal ranges. Only the tumor marker was elevated (Ca 15-3: $56 \mathrm{U} / \mathrm{mL}$, accepted upper limit of norm of $35 \mathrm{U} / \mathrm{mL})$.

Initially we perfomed a spiral contrast-enhanced CT of the abdomen, which showed only liver steatosis of grade II-III. Ultrasound examination of the heart presented a pericardial effusion of almost $500 \mathrm{~mL}$ which did not interfere with the left ventricular ejection fraction (70\%) and the pump function of the heart. As a result, according to the cardiologist, no pericardial penetration was needed. The effusion was diminished to $200 \mathrm{~mL}$ after a week's treatment with diuretics.

At this time (February 24, 2009) we started a chemotherapy regimen but only with docetaxel $80 \mathrm{mg} / \mathrm{m}^{2}$ because of the patient's refusal to be treated with epirubicin (due to her fear of alopecia). Three cycles of the above-mentioned scheme were performed after which repeated laboratory examinations, including $\mathrm{CBC}$, revealed normal results. The control CT scan of the lung in April 2009 manifested a lack of difference in comparison to the initial scan, and the heart ultrasound presented a persistent effusion of around $100 \mathrm{~mL}$. The tumor marker now was $83 \mathrm{U} / \mathrm{mL}$. At this time a thoracic paracentesis was performed with the evacuation of $1000 \mathrm{~mL}$ of exudates.

At the beginning of May, since the patient had already experienced partial alopecia, epirubicin $80 \mathrm{mg} / \mathrm{m}^{2}$ was added to the cytostatic regimen. Now a prophylactic treatment with GCSFs was established from the second until the seventh day after each cycle. Eight days after the first doublet chemotherapy, $\mathrm{CBC}$ were examined and the results were within the normal range. The treatment continued.

The patient was hospitalized seven days after the second doublet chemotherapy infusion. She complained of severe pain in her left thigh and lumbar region, and of urinary disturbances described as pain and itching. The patient was not febrile and the physical examination was normal, including the mucosal status. Her relatives revealed that a week before she had used an intramuscular nonsteroidal anti-inflammatory drug for her pain in the lumbar region, applying it herself to the left hip. The $\mathrm{CBC}$ showed neutropenia with a white blood count $\left(\mathrm{WBC}\right.$ ) of $0.63 \times 10^{9} / \mathrm{L}$ and an absolute neutrophil count $\left(\right.$ ANC) of $0.33 \times 10^{9} / \mathrm{L}$. Hemoglobin $(\mathrm{Hb})$ was $111 \mathrm{~g} / \mathrm{L}$ and thrombocytes (Plt) were $165 \times 10^{9} / \mathrm{L}$. An X-ray of the lumbar section showed osteochondrosis in L3, L4, and L5. Since the patient was nonfebrile, no microbiologic tests were performed (as this is a standard approach in our department). Immediately treatment with antibiotics, antifungal, antiinflammatory and sedative drugs, as well as GCSFs were started, but in the course of the day the pain increased and there was no obvious improvement in her condition. A small, palpable, pale grayish lesion on her left thigh appeared and grew bigger for several hours; the same lesion appeared on her left shoulder. A CT scan of the thighs was performed which revealed a diffuse emphysematous phlegmon of both thighs, greatly expressed on the left (Figure 1). The patient now experienced breathing difficulty, and she was immediately transferred to our surgical department. Her laboratory results showed progressive anemia $(\mathrm{Hb} 80 \mathrm{~g} / \mathrm{L})$, thrombocytopenia (Plt $50 \times 10^{9} / \mathrm{L}$ ), liver and kidney dysfunction, as well as coagulopathy with diminishing fibrinogen. No surgical intervention was attempted. Ten hours after hospitalization the patient died. No autopsy examination was performed following the wishes of her family.

\section{Discussion}

Chemotherapy-induced neutropenia is often a dose-limiting side-effect of cytostatic treatment. In rare cases such a complication can result in a life-threatening situation.

Recently the development and prophylactic application of GCSFs has revolutionized oncology practice. ${ }^{3}$ GCSFs significantly diminish the cases of febrile neutropenia (FN) and improve the chemotherapy treatment as a result. Subsequent clinical trials and meta-analyses have proven that in many tumor types primary prophylaxis with GCSFs reduces the incidence of febrile neutropenia (FN), FN-related hospitalizations, infection-related mortality, and the need for chemotherapy dose modification, compared with placebo or no treatment. Prophylactic use of these agents has not only enabled development of more aggressive chemotherapy regimens, including dose-dense chemotherapy, but also treatment of a broader range of patients. ${ }^{4,5}$

Nevertheless there are still cases when the prophylactic use of GCSFs seems to be insufficient. In our patient, neutropenia was observed despite adequate postchemotherapy prophylaxis. At the outset no signs of inflammation had been detected: no temperature, no mucosal changes in the mouth, no oral candidiasis. This is why we commenced only 

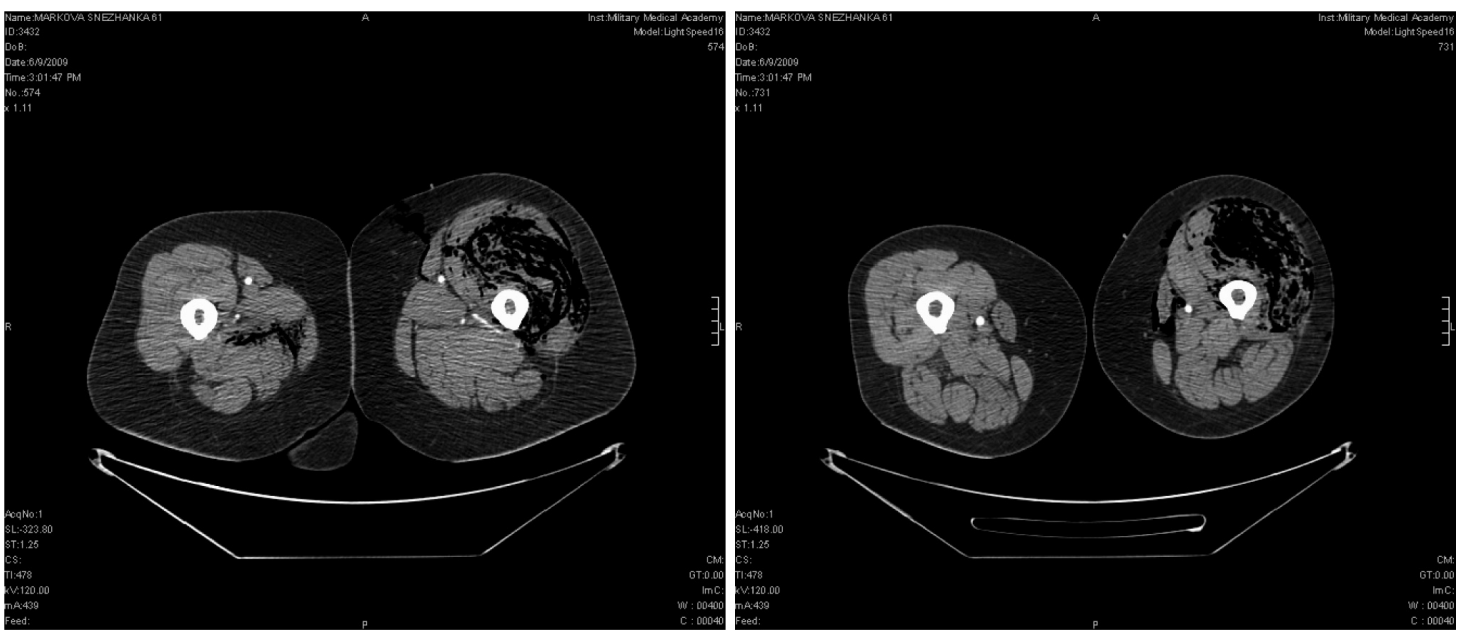

Figure I Diffuse emphysematous phlegmon of both thighs, mostly on the left.

a standard treatment for neutropenia, without performing a microbiological verification. The results of all our attempts to halt, or at least to limit the process were negative only 10 hours after hospitalization death occurred. The information from the patient's family of the intramuscular intervention (a perfect entrance for an anaerobic infection), the laboratory results $\left(\mathrm{WBC} 0.6 \times 10^{9} \mathrm{~L}\right)$ and the CT data for a diffuse emphysematous phlegmon of the thighs made us conclude that the described case was most likely caused by an anaerobic bacteremia from an unknown microorganism with fulminate progression. The extremely rapid course and blurred picture of the disease did not allow us to perform a microbiological verification at the very beginning.

Similarly, a microbiological verification was not established during an autopsy because of the family's refusal for an autopsy to be conducted.

Nevertheless we believe that the examinations we performed during the short time that the patient was at our department might prove the presence of anaerobic inflammation: a process which had occurred during a prophylaxis with GCSF after a chemotherapy course. The problem of chemotherapy-induced neutropenia is not completely solved and we are a long way from offering our patients a safe way to manage this complication. New projects and clinical trials are necessary to update and elaborate the present standards for neutropenia treatment.

\section{Disclosures}

The authors report no conflicts of interest in this work.

\section{References}

1. Cameron D, Management of chemotherapy-associated febrile neutropenia. Br J Cancer. 2009;101:S18-S22.

2. Kelly S, Wheatley D. Prevention of febrile neutropenia: use of granulocyte colony-stimulating factors. Br J Cancer. 2009;101:S6-S10.

3. Liutkauskiene S, Sveikata A, Juozaityte E, et al. Safety and efficacy study of the recombinant granulocyte colony-stimulating factor for prevention of neutropenia and neutropenia-related complications in women with metastatic breast cancer receiving docetaxel/doxorubicin, Medicina (Kaunas). 2009;45(8):600-606

4. Soong D, Haj R, Leung MG, et al. High rate of febrile neutropenia in patients with operable breast cancer receiving docetaxel and cyclophosphamide. J Clin Oncol. 2009;27(26):e101-e102.

5. Renwick W, Pettengell R, Green M. Use of filgrastim and pegfilgrastim to support delivery of chemotherapy: twenty years of clinical experience. BioDrugs. 2009;23(3):175-186.

\section{Publish your work in this journal}

The International Medical Case Reports Journal is an international, peer-reviewed open-access journal publishing original case reports from all medical specialties. Previously unpublished medical posters are also accepted relating to any area of clinical or preclinical science. Submissions should not normally exceed 2,000 words or

\section{Dovepress}

4 published pages including figures, diagrams and references. The manuscript management system is completely online and includes a very quick and fair peer-review system, which is all easy to use. Visit $\mathrm{http}: / / \mathrm{www}$.dovepress.com/testimonials.php to read real quotes from published authors. 